\title{
26482 - MISREPRESENTED BRAIN TUMOR RESULTS IN ITP EVALUATION
}

Don Woods MD, Rainier Guiang, MD; Jeffrey Janata, PhD; Margaret Kotz, University Hospitals Of Cleveland, Cleveland, OHIO, USA 